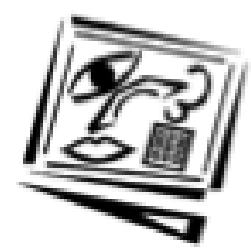

\title{
Multicampus video on demand at Monash University
}

\author{
Philip Branch and Bruce Tonkin \\ Monash University
}

\begin{abstract}
This paper describes research into multi-campus, video-on-demand at Monash University and its application to education. In education, video is used in a highly interactive way, for which traditional analog video tape is poorly equipped. The Advanced Network System Performance Application Group and Monash's Department of Visual Arts recognised the potential of interactive video-on-demand and began a series of trials. The first used a small system located in the Visual Arts Library at Monash's Clayton campus. Academics, librarians and students were involved in evaluating the technology for teaching, research and study. This was followed by a larger, multi-campus trial, where video-on-demand was distributed from a central point on the Clayton campus to the main libraries at Monash's Clayton and Caulfield campuses using a high speed network. The trial is being extended to Monash's Berwick campus where interactive video-on-demand is being used as a research tool and to allow experimentation with more complex systems. This paper describes the outcomes, the difficulties, the potential for video-on-demand, and the factors that may affect its eventual uptake.
\end{abstract}

\section{Introduction}

Technological development in video delivery systems has made enormous gains in the last few years. There are now many digital video services that can be used in education. These include video conferencing, broadcasting, CD-ROM and video-on-demand. This paper describes our experience in developing and trialing video-on-demand.

In 1995, the Advanced Network System Performance Application Group (ANSPAG) began investigating interactive video-on-demand. ANSPAG is a joint venture between Telstra, Siemens and Monash University, formed to investigate potential applications of some of the newly emerging broadband technologies. Because of their heavy use of analog video tape and the recognition of its limitation, as well as their interest in multimedia, the Visual Arts Department at Clayton were interested in becoming an early adopter of the technology. 
Visual Arts students and academics use analog video tape to study films, television and plays. However, analog video tape has limitations for study since it caters for interactive behaviour poorly. Often a student will want to go directly to a particular scene in a video, examine it a few times and then finish. To do this with analog video tape can be quite cumbersome. Also, integration of analog video tape with other media is difficult, if not impossible, so to develop a multimedia package incorporating video for student teaching requires alternative ways of delivering video.

Analog video tape presents management problems for librarians as well. Because of the heavy use of analog video tape by students, tapes have a very short life. Also, in a multi-campus environment, ensuring availability of a sufficient number of tapes in all branch libraries places a substantial administrative load on the library.

The trials had a short term goal of identifying the advantages and disadvantages of video-on-demand as a way of delivering video in an educational environment. However, an equally important, but more long term goal of the trials was for all participants to understand different aspects of the technology. As a result, during the trials a number of parallel streams of learning occurred. Visual Arts academics, students and librarians learnt of the potential of the technology while ANSPAG engineers learnt how video is used by Arts students and academics, what the difficulties are for librarians in managing video, and what technical issues there are in installing video-on-demand technology and high speed networks. As well, Engineering and Visual Arts students were involved in the trials, either implementing or evaluating alternative approaches to problems that arose. This cross-disciplinary learning has been one of the most rewarding aspects of the project.

The importance of video in education has been identified in surveys of overseas trials. Walsh and Reese (1995) looked at distance education networks in the USA, and concluded that "When combined with other media, video has proven to be a highly effective way of getting and holding students' attention, so real learning can take place". In a literature review of technology in the education system, Wellburn (1997) lists some of the benefits of video technology, but observes that ".these benefits do not happen in some miraculous way simply because the technology has been provided. ...there is a need for training and support at all levels."

While there is quite a large literature on video in general in education, there is much less on interactive video-on-demand, partly because of its novelty, and partly because of its (until recently) considerable expense. Papers describing technical aspects of low cost video-on-demand trials in 
education have been written by Tobagi (1995) and Vickers (1995). A number of universities have installed video-on-demand systems, including Swinburne University and the University of Queensland.

The rest of the paper consists of an overview of video-on-demand technology, discussions of the first and subsequent trials and finally a discussion of the barriers to the widespread deployment of interactive video-on-demand.

\section{Video on demand technology}

Video-on-demand has become a feasible service because of the development of high quality video compression techniques, development of high speed network technology and affordable high power computing.

Video-on-demand systems are made up of a server on which digitised video is stored, a network that carries the digital video, and clients that display the video. If the video is stored on analog tape then an encoder or encoding service is also needed. A client can be either a Personal Computer or a television set connected to a set top box. In our trials the clients have all been Personal Computers. A schematic of a video-on-demand system is shown in Figure 1.

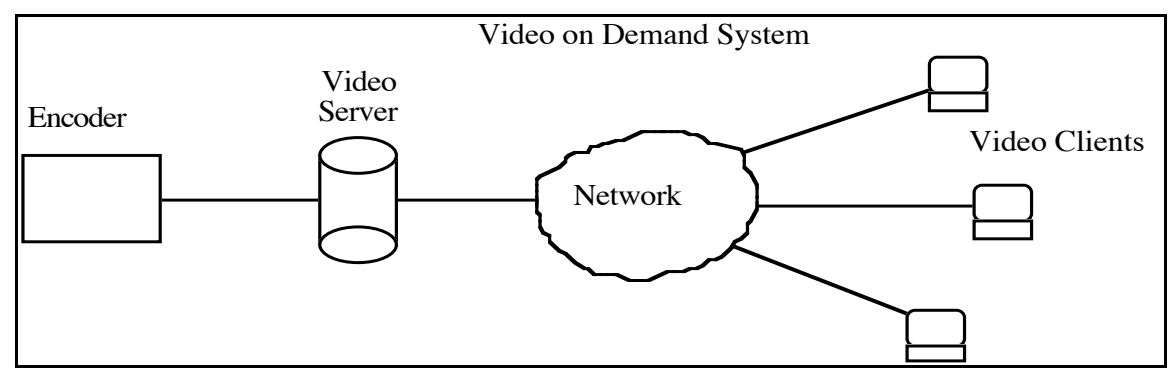

Figure 1. Video on demand system

Video is converted into digital format through taking a signal from an analog video source (such as beta-cam, VHS or 1 inch tape) and feeding it through an encoder to produce a file of digital video. The most popular format for digital video is MPEG-1 (from the Moving Pictures Expert Group). MPEG-1 is optimised to produce video streams at 1.5 to 2.5 Megabits per second. A good introduction to the technical aspects of MPEG-1 encoding has been written by LeGall (1991).

Once encoded the digital video is loaded onto a video server and becomes available to video clients on demand. There are no broadcasts with video- 
on-demand. A video-on-demand client requests the video, which is then delivered instantly. There is a single channel from each client through to the server.

The functionality each viewer has is similar to that of a VCR system. A viewer might pause, fast-forward or rewind without affecting any other viewer. Additional functions such as frame by frame viewing, zoom and skip to a particular scene are also available.

These features are of limited use in entertainment where the video is usually viewed from beginning to end with little or no interruption, but are useful for education and research. For example, students studying a play that has been put on a video server might want to examine a particular scene many times to examine the set, the performance, the lighting and so on. The interactivity of video-on-demand provides the opportunity for many potential applications.

However, this interactivity and control places considerable demands on the three main components of the video-on-demand system: the server, network and client. The server has to support an independent video stream to every client, rather than broadcasting a single stream, and so must be able to read data from disk storage onto the network at a very high rate. Video files are large, typically 500 Megabytes to 1 Gigabyte for every hour of video, so the server must be equipped with large amounts of storage space. The network must be able to deliver each frame of the video with very tight limits on delay and delay variation. Most digital networks, such as shared Ethernet, have been developed for data applications and handle video poorly. New network technologies, such as Switched Ethernet and Asynchronous Transfer Mode (ATM) need to be used to deliver high quality video. Uncompressing video at the client is computationally intensive. A video sequence contains a great deal of redundant information that can be removed without visual impact, resulting in large savings in network capacity and video storage space. However, reconstructing the video at the video client requires a great deal of processing power. Consequently, to provide full screen, 30 frames per second video, a hardware decoder is usually installed in the video client.

\section{Small scale video on demand trial}

ANSPAG began investigating possible applications of some of the emerging video and communications technologies in 1994. As part of this investigation, and following discussions with the Visual Arts Librarian at the Clayton Campus, Monash, a small scale video-on-demand system was developed and installed in the Visual Arts Library for a technology trial. 
Visual Arts were attracted to this technology for several reasons. The first is that much of their material is video based. Students study classic films, television and documentaries as part of their course. However, access to video for students is often difficult. The classes are large, and availability of material is often limited. The second reason for Visual Arts involvement is that analog video tapes are not an ideal medium for film and television study. Under the intense use students give them, analog video tapes wear out quickly. Film and Television study involves a great deal of analysis of particular scenes, random jumps to other scenes, descriptions of scenes and annotation, which analog video tape is poorly equipped for. The third main reason for Visual Arts involvement is the interest of staff and students in multimedia and digital technology.

Video-on-demand trials began in second semester, 1995. A full account of this trial can be found in Branch and Durran (1996). At the time we began looking at video-on-demand, there were no low-cost systems available. We were able to gain a headstart in investigating this technology by developing a simple, prototype system. In this system, the video server was a high performance Personal Computer with two high speed SCSI disks, and multiple Ethernet cards. Each video client was connected directly to the video server. The server could support up to seven such attachments.

The material used in the trial was selected from the Department of Visual Arts teaching program. It included about 90 minutes of television and film excerpts. Encoding was done with Siemens' Eikona system, developed at Monash University. We used MPEG-1 encoding, and because we were interested in perceptions of video quality, we encoded material at two rates: 1.5 Mbps and 2.5 Mbps.

The system was made available to Visual Arts students, academics and librarians who, after using it, were then informally interviewed. Thirty people were interviewed. Of particular interest was what participants felt was useful, what wasn't, what were the weaknesses of the system, how it compared with analog video tape, and what applications it might be suitable for.

Our main interest was in the human factors associated with video-ondemand. We were less interested in the technology, than in what the technology could do, and whether people who use video for their work, felt that the technology could be of use to them.

We found that academics and students identified issues associated with learning, while Librarians identified issues of management and delivery. 
From the interviews, it seemed that interactive video-on-demand had a number of advantages over analog video tape:

- Having video integrated into the Personal Computer environment was very useful. Students could take notes on a word processor while viewing the video. The interactive control meant that the scenes of interest could be viewed immediately.

- Librarians felt that it could alleviate problems of access and management of video since video on the server is difficult to pirate, doesn't wear out with use and can't be lost or stolen in the same way that individual video cassettes can.

However, some weaknesses were identified.

- Copyright is a difficult area with this technology, and raises many questions about royalty payments, the basis for royalty payments, payper-view and pay-per-copy

- A user interface that might be suitable for entertainment video was hopelessly inadequate for interactive study, and needed many enhancements.

- Encoding quality had to be very good. Although there is some novelty in full screen video on a Personal Computer it rapidly wears off, and students will not accept a video at less than analog tape quality.

- The few hours capacity on the server was not enough. Considerably more is needed for a full course.

The response from participants in the first trial was that video-on-demand has a lot of potential, but the issues outlined above needed to be dealt with before it could be widely used.

\section{Multi-campus video on demand trial}

\section{A wide area video on demand system}

To address some of the issues identified in the first trial, and to extend understanding of the many technical issues involved, ANSPAG, Visual Arts and Monash Library carried began a larger, multi-campus trial in second semester, 1996. Visual Arts used the system to teach a course on documentaries at both Clayton and Caulfield campuses.

The system used for the second trial was much more sophisticated than that of the first trial. It was multi-campus, could support many more users concurrently and store ten hours of video. As part of the trial, 
Asynchronous Transfer Mode (ATM) network technology was used from the server through to the client. The clients were Personal Computers located in the main libraries at Clayton and Caulfield campuses. Each Personal Computer was equipped with an MPEG decoder card and an ATM Network Interface Card.

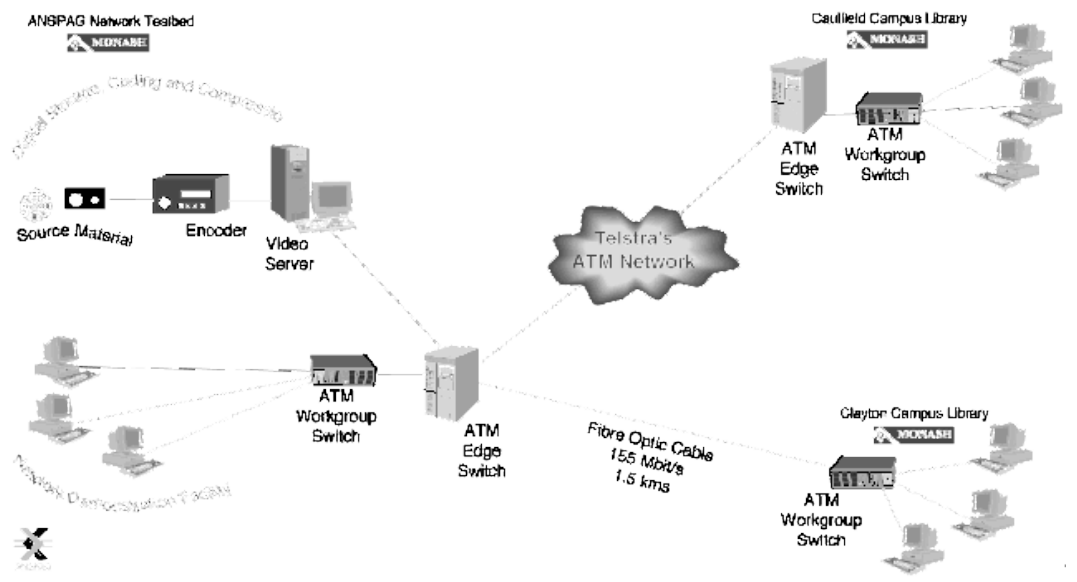

Figure 2. Platform for second video on demand trial

This second trial required a substantial investment in network equipment. The network developed is shown above.

The networking infrastructure installed included a video server, workgroup switches and ATM network interface cards from First Virtual Corporation (FVC), a campus switch from FORE (Forerunner ASX-300) and two Newbridge 3150 edge switches. The workgroup switches provided ATM to each Personal Computer at 25 Mbps over standard UTP cables. ATM at $155 \mathrm{Mbps}$ was used to connect buildings on the same campus through optic fibre. Connection between Clayton and Caulfield campuses was through Telstra's Experimental Broadband Network at 34 Mbps.

Network interface cards connect Personal Computers to a workgroup switch over standard unshielded twisted pair cable. They provide a maximum data rate of $25 \mathrm{Mbps}$. Workgroup switches concentrate multiple $25 \mathrm{Mbps}$ connections into a single $155 \mathrm{Mbps}$ connection. Campus switches (or backbone switches) connect multiple workgroup switches located on a campus or in a large building. They can also provide direct $155 \mathrm{Mbps}$ connections to work stations requiring very high bandwidth. Edge switches provide wide area connectivity, through connecting into a carrier's wide area service. 


\section{User interface}

One of the parallel streams of learning during the trial was the involvement of final year engineering students. As an Honours project for two final year students, a more appropriate user interface was developed. This is described in more detail in Branch (1996). The students conducted surveys and interviews with final year Visual Arts students, academic staff and librarians to identify additional functions required of the interface. They also worked with Telstra Research Laboratory's Socio-Technical group in the design of the interface.

The students adopted an iterative approach to developing the interface. Once the need for a feature was identified, it would be implemented and feedback sought from Visual Arts staff and students as to its effectiveness. Following this, modifications would be carried out, and the process repeated.

Some of the features implemented included obvious requirements for interactive viewing such as fast forward, slow motion, high quality stills, and zoom; but it also included more novel suggestions such as annotating parts of the video during playback and selecting and constantly looping on a sub-part of the video.

Visual Arts students have a wide range of computer expertise. Some, particularly those interested in multimedia, are very comfortable with computers, whereas others only use computers for word processing. Consequently, the interface needed to be simple for novice users, but able to provide sophisticated facilities for more experienced users.

Figure 3 shows the first implementation of the interface. The design used a Video Cassette Player metaphor, so that students could carry out the standard functions simply and easily, making training straight forward. The user interface was designed to be simple for novice users, but with many advanced features and shortcuts for experienced users. The interface contained the standard trick modes of fast forward, fast rewind, jump to the end and jump to the beginning of the video. However, many more advanced options were made available through the pull-down menus. This first version was written in Microsoft Visual Basic using the standard MCI library.

Being able to take notes on the Personal Computer while viewing the video was the most asked for feature. This was implemented by initiating the standard word processing package that then runs concurrently with the video. 
Annotating scenes of interest and importance in the video is a useful feature. This was implemented through a system of 'bookmarks'. A bookmark includes text, which can be viewed through a pull-down menu, or by placing the mouse over the bookmark on the slider. Bookmarks can be edited, saved onto a bookmark file, or a previously created file of bookmarks can be loaded. The bookmark approach makes new ways of teaching with video possible. The teacher can issue a file of bookmarks for a particular video, which the students can then use to guide them in understanding the video.

Depending on whether the student is taking notes or simply viewing, different screen sizes are necessary. The interface provided three default sizes for the video window. These are one third of a screen, one half of a screen and full screen. The user can drag the window to other sizes if needed, but can always return to one of the default sizes.

A useful feature for preparing assignments is extraction of an image from the video for later insertion in a word processing document. The interface allows stills to be extracted in bitmap format onto the Windows notepad or onto a bitmap file, from which it can be readily copied into a word processing document.

Being able to continually review a small part of a video is important. In 'shot analysis' a scene is reviewed many times. The interface allowed a loop to be inserted, that caused the video denoted by the loop to be continually replayed.

Many of the functions, such as bookmarks, notes and image extracts produce data files. The interface, by default, writes these to the floppy disk in the Personal Computer, unless otherwise specified.

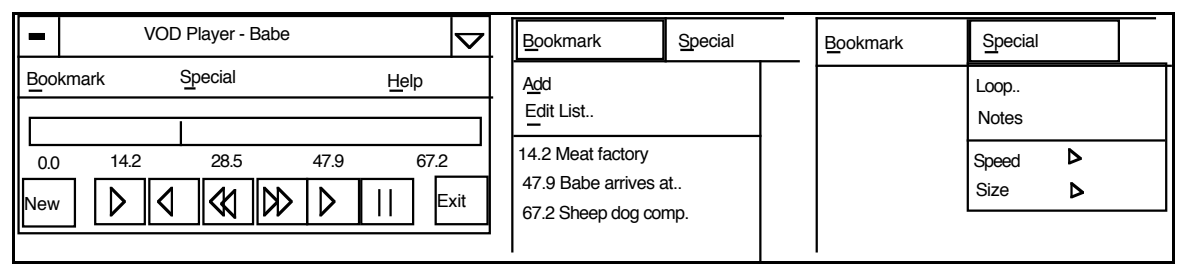

Figure 3. Personal computer based video-on-demand player

\section{Student response}

Throughout the trial, we have collected questionnaires from students whenever they use the system. We hope to use this information to gain knowledge as to viewing habits of students, and learn how the service 
might be improved. Students were surveyed before the system was introduced to obtain information about their habits of watching video and the need for video services.

Before installing the system, we surveyed students to find out about their viewing habits, whether or not they experienced difficulty in obtaining video and how they used video. Generally we found that most students experienced some difficulty in obtaining video, they used the limited interactivity provided by VCRs a great deal and, apart from the in-class initial screening, would usually not watch the video from beginning to end a second time.

At the end of the trial, students were surveyed to find out whether they had used the system, which films they had viewed with it, what features they had used and whether they had any other comments.

Of the 200 students in the class taught in second semester 1996, 60 became regular users of the system. We have found the student response to the system has been enthusiastic once initial reluctance to try it is overcome. For students who have become familiar with the system, it is the method of choice of viewing video. Almost all responses to our survey were positive. Typical comments included 'Easier and better than a video', 'Very convenient, easy to use', 'Excellent Innovation' and from one student who had mastered the system and used all the features, 'Brilliant'. An interesting comment was 'Picture quality pretty good (unexpectedly)'.

However, there was a reluctance, particularly among female students, to try the technology. Some would refuse point-blank, preferring to wait for the analog video tape to become available rather than use the system. To try and overcome this, one of the librarians (female) described the system and its capabilities during a Visual Arts lecture, and conducted some introductory seminars for students. We believe this was useful, but there is still a noticeable reluctance among female students to try the technology.

Of the students who used the system, our survey shows that being able to jump directly to the scene of interest, vary the size of the displayed video and take notes are the most attractive features, and were used by most students. We found that the other features were used much less. We believe this is because they are more difficult to use and less familiar than other functions seen on a standard video-cassette player. We have since attempted to simplify them and make them easier to use. 
One thing that many students complained of, regardless of their familiarity or experience with the system was that there were not enough titles available online. A full semester course on film includes twelve feature films, each between one and two hours duration. We were only ever able to have four or five online at any one time. Being able to make a large number of titles available online is one of the big research challenges for interactive video-on-demand.

\section{Extension to Berwick Campus}

The next major step in video-on-demand at Monash is to extend the trial to the Berwick campus. This began during first semester, 1997. At Berwick, video-on-demand is to be used primarily as a research tool, unlike the previous trials where it has been used in teaching. Research areas include the use of video for communications, marketing in Australia and Asia, and Tourism.

To enable experimentation with a distributed, multi-server system, a separate server has been installed at Berwick. This will enable ANSPAG to research distributed server management and load sharing.

Figure 4 shows the proposed system. Video is delivered across a network from a Windows NT Server which is a front end for the distributed servers.

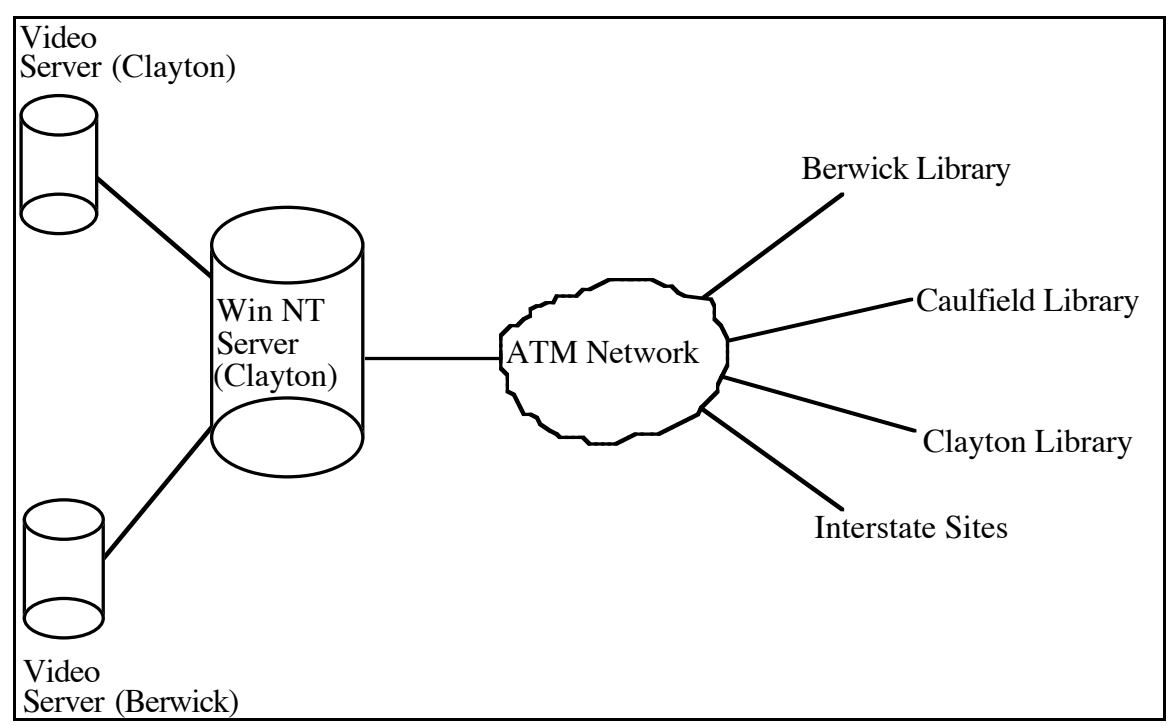

Figure 4. Distributed video on demand system 


\section{Conclusion}

Although our work has shown that video-on-demand is likely to become an important educational technology, there are still barriers to its widespread deployment. These are mostly economic and legal, rather than technical or educational. In particular, wide area bandwidth needs to become available at a reasonable price, there needs to be ready access to large digital video libraries and copyright law needs clarification.

Wide area bandwidth in Australia is still expensive by international standards. However, some recent developments suggest that this situation is improving. In the metropolitan areas of the major cities, coaxial cable has been rolled out for the deployment of analog pay TV. This cable can also be used for digital data services using cable modems which might be suitable for interactive video-on-demand. In outer metropolitan areas, ADSL technology might enable video-on-demand to be used over existing phone lines. Both major carriers have promised to provide commercial ATM services within the next twelve months. Another possibility for the provision of cheap bandwidth is, since telecommunications deregulation, some organisations with large, underused, private networks may act as carriers. Alternatively, the major telecommunications carriers might offer video-on-demand services themselves. An educational organisation might rent space from the telecommunications carrier which would then be available over the carrier's network.

Digital video requires large amounts of storage, even when compressed. To increase the number of titles online, there is a need for large libraries of digital material from which videos can be accessed directly or loaded onto a local server as needed. Library cataloguing, searching and management systems need to be developed to support this.

Copyright needs to be resolved. Simple guidelines and mechanisms for payment of royalties need to be established, along with methods to avoid illegal copying and distribution.

Video-on-demand opens the way to many interesting teaching, research and industrial applications. It is easy to envisage being able to access from video servers almost anywhere, otherwise unobtainable video material.

Video-on-demand has been successfully deployed at Monash University in teaching and research trials. From these trials factors affecting the success of video-on-demand have been identified. These are not just technical, but are also human, economic and legal. Once these issues are dealt with, 
video-on-demand is likely to be an important teaching and research technology.

\section{Acknowledgments}

The authors gratefully acknowledge the support of Telstra, Siemens Ltd, Monash University and the Australian Government's Cooperative Research Centre program.

\section{References}

Branch, P., Durran, J. (1996). Personal computer based video on demand trials, Proceedings of EdTEch'96, Melbourne, July 1996, 21-24.

Branch, P. (1996). Video on demand trials at Monash University, Proceedings of the Virtual University Symposium, Melbourne, November 1996.

Binns, G., Branch, P. (1998). McIver (Multicampus Interactive Video Education Resource) and video-on-demand - the next step - an application in an academic environment. Victorian Association for Library Automation Biennial Conference, Melbourne, January 1998.

Branch, P., Newstead, A., Kaushik, R. (1996). Design of a wide area, video on demand user interface. Proceedings of the Australian Telecommunications Network and Applications Conference. Melbourne, December 1996.

Cooper, R. (1995). Piloting the information superhighway. Proceedings of the Australian Telecommunications Network and Applications Conference. Sydney, December 1995, vii-xiii.

LeGall, D. (1991). MPEG: A video compression standard for multimedia applications. Communications of the ACM, 34(4), 47-58.

Tobagi, F. (1995). Distance Learning with digital video. IEEE Multimedia, Spring, 90-93.

Vickers, B. J., Chen, L., Kim, J. B., Suda, T., Myers, S., Lesnansky, S. (1995). The distributed and interactive courseware environment. Proceedings of the 5th Workshop on Future Trends of Distributed Computing Systems. Cheju Island, Republic of Korea, Aug. 1995.

Walsh, J. and Reese, B. (1995). Distance learning's growing reach. THE Journal, Vol. 22.

Wellburn, E. (1997). The status of technology in the education system: A literature review. http://www.etc.bc.ca/lists/nuggets/EdTech_report.html

Philip Branch and Bruce Tonkin

Advanced Network System Performance and Application Group (ANSPAG)

Department of Electrical and Computer Systems Engineering

Monash University, Clayton, Vic 3168.

philip.branch@eng.monash.edu.au

bruce.tonkin@eng.monash.edu.au 